Fecha de recepción:

Fecha de evaluación: Fecha de aprobación: 4 de diciembre de 2018 14 de diciembre de 2018

\title{
El justo comunitario del patio de los presos políticos de La Picota: una aproximación desde las voces LGBT que lo habitan*
}

Para citar este artículo

Ortiz, C. (2019). El justo comunitario del patio de los presos políticos de La Picota: una aproximación desde las voces LGBT que lo habitan. Revista Vía luris ( $\left.\mathrm{n}^{\circ} 26\right)$, pp. 125-145.

\begin{abstract}
RESUMEN
Las indignas condiciones del actual sistema penitenciario y carcelario colombiano exigen que buena parte de la población privada de la libertad desarrolle dinámicas regulatorias de comportamientos basadas en la criminalidad y la violencia como la mejor opción de sobrevivir intramuros; sin embargo, una minoría parece resistirse a esas formas. El presente artículo tiene el propósito de estudiar, desde su carácter comunitario y político, una expresión de pluralismo jurídico que tiene lugar en el pabellón 4, de la estructura 1, del complejo carcelario y penitenciario metropolitano de Bogotá "Comeb" (La Picota); o como se le denomina: "patio de los presos políticos", donde habitan los guerrilleros de las FARC-EP, y gran parte de la comunidad de lesbianas, gays, bisexuales, y personas transgénero (LGBT). Para ello se hace un abordaje cualitativo no experimental, con un enfoque metaepistemológico, mediante el estudio de caso de la comunidad LGBT y la entrevista dialogada con uno de sus líderes. De manera complementaria se hace una aproximación metodológica cuantitativa, principalmente a través del método de la encuesta. Así, el principal resultado es la sistematización, presentación y explicación del justo comunitario del pabellón 4, que se configura más democrático, igualitario, menos violento y discriminatorio con respecto a los demás patios. Esto permite comprender que en las prisiones interactúan y confluyen diversas expresiones regulatorias de conductas que cambian entre cada patio, de cada centro penitenciario.
\end{abstract}

* Este trabajo corresponde a uno de los productos del proyecto de investigación: "Cárceles para la Paz" de la Escuela de Justicia Comunitaria de la Universidad Nacional de Colombia. Periodo: (2017-2018) Bogotá (Colombia).

** Investigadora de la Escuela de Justicia Comunitaria de la Universidad Nacional de Colombia. Abogada y politóloga de la Universidad Nacional de Colombia. Actualmente cursando estudios de especialización en Derechos Humanos y Derecho Internacional Humanitario de la misma universidad. ORCID https://orcid.org/0000-0003-0523-5813. Correo electrónico: caortizd@unal.edu.co
DOI: https://doi.org/10.37511/viaiuris.n26a7

Esta obra está bajo una Licencia Creative Commons AtribuciónCompartirIgual 4.0 Internacional.
Palabras clave

Pluralismo jurídico, justicia comunitaria, Cárcel,

LGBT, FARC-EP, Sistema penitenciario y carcelario, instituciones totales. 


\title{
The community justice of the courtyard for political prisoners in La Picota: an approach through LGBT voices that inhabit it
}

\author{
Camila Andrea Ortiz Díaz
}

\begin{abstract}
The unworthy conditions of the current colombian penitentiary and prison system require that the prison population develop regulatory dynamics of behaviors based mainly on crime and violence as the best option to survive intramurally. The present article has the purpose of studying, from its community and political character, an expression of legal pluralism that takes place in pavilion 4, of structure 1, of the prison and metropolitan penitentiary complex of Bogotá "Comeb" (La Picota); or as it is called: "courtyard of political prisoners", where the FARC-EP guerrillas live, and a large part of the lesbian, gay, bisexual, and transgender community (LGBT). For this, a qualitative non-experimental approach is made, with a meta-epistemological approach, through the case study of the LGBT community and the dialogue interview with one of its leaders. In a complementary way, a qualitative methodological approach is made, mainly through the survey method. Thus, the main result is the systematization, presentation and explanation of the community justice of pavilion 4, which is more democratic, egalitarian, less violent and discriminatory with respect to the other courtyards. This allows us to understand that in prisons various regulatory expressions of behaviors that change between each courtyard, of each penitentiary center, interact and converge.
\end{abstract}

\section{Keywords}




\section{A feira comunitária do pátio dos presos políticos do pelourinho: uma aproximação das vozes LGBT que a habitam}

\section{Camila Andrea Ortiz Díaz}

\section{RESUMO}

As condições indignas da atual prisão e sistema prisional colombiano exigem que grande parte da população privada de liberdade desenvolva dinâmicas regulatórias de comportamento baseadas no crime e na violência como a melhor opção para sobreviver intramuralmente; no entanto, uma minoria parece resistir a essas formas. Este artigo tem como objetivo estudar, de sua comunidade e política, uma expressão do pluralismo jurídico, que tem lugar no pavilhão 4 da estrutura 1, o metropolitano prisão e prisão complexo Bogotá "Comeb" (O Picota); ou como é chamado "pátio dos prisioneiros políticos", habitadas pelas FARC-EP, e grande parte da lésbicas, gays, bissexuais e transgêneros (LGBT) isso requer uma abordagem qualitativa é feita não experimental, com uma abordagem metaepistemológica, através do estudo de caso da comunidade LGBT e a entrevista de diálogo com um de seus líderes. Uma maneira adicional de abordagem metodológica quantitativa é feita, principalmente através do método de pesquisa. O resultado é a sistematização, apresentação e explicação do Justo Comunitario do pavilhão 4, que é mais democrático, igualitário, menos violento e criminatória em relação aos outros pátios. Isso nos permite entender que nas prisões, várias expressões regulatórias de comportamentos que mudam entre cada pátio, de cada centro penitenciário, interagem e convergem. 


\title{
La foire communautaire de la cour des prisonniers politiques du pilori: une approche des voix LGBT qui I'habitent
}

\section{Camila Andrea Ortiz Díaz}

\begin{abstract}
RÉSUMÉ
Les conditions indignes des prisons et des systèmes pénitentiaires colombiens actuels imposent à une grande partie de la population privée de liberté de développer une dynamique réglementaire de comportement basée sur le crime et la violence, meilleure option pour survivre de manière intramurale; cependant, une minorité semble résister à ces formes. Le présent article a pour objet d'étudier, de par son caractère communautaire et politique, une expression du pluralisme juridique qui s'inscrit dans le pavillon 4, de la structure 1, du complexe pénitentiaire et pénitentiaire métropolitain de Bogotá « COMEB » (La Picota); comme on l'appelle: " patio des prisonniers politiques », où vivent les guérilleros FARC-EP, et une grande partie de la communauté lesbienne, gay, bisexuelle et transgenre (LGBT) pour laquelle une approche qualitative est adoptée non expérimentale, avec une approche méta-épistémologique, à travers l'étude de cas de la communauté LGBT et l'entretien de dialogue avec l'un de ses dirigeants. Une approche méthodologique quantitative est également mise en œuvre, principalement par le biais de la méthode d'enquête. Le résultat est la systématisation, la présentation et l'explication du Justo Comunitario du pavillon 4, qui est plus démocratique, égalitaire, moins violent et moins criminatoire par rapport aux autres cours. Cela nous permet de comprendre que dans les prisons, différentes expressions réglementaires de comportements qui changent entre chaque patio, chaque centre pénitentiaire, interagissent et convergent.
\end{abstract}

\section{Mots-clés}

Pluralisme juridique, justice communautaire, prison, LGBT, FARC-EP, système pénitentiaire et pénitentiaire, institutions globales. 


\section{INTRODUCCIÓN}

La cárcel en Colombia parece llevar en su esencia las dinámicas de guerra que han atravesado al país, convirtiendo en simple quimera el cumplimiento del fin misional del Sistema Penitenciario en Colombia, señalado por el exdirector general del INPEC Saúl Torres en su entrevista con KienyKe Editorial (2014): la "socialización adecuada para que los internos, de regreso a la libertad, no vuelvan a cometer los mismos delitos" (p. 1).

Pese a la cruda realidad donde la cárcel se configura como centros de criminalidad, violencia y drogadicción, el presente estudio encontró una excepción, la administración de justicia de un patio que no está regido bajo dichas lógicas. Sin embargo, a través del estudio de caso de la comunidad de lesbianas, gays, bisexuales, y personas transgénero -LGBT-, se evidencia que, para el grueso de la población privada de la libertad, la justicia es un propósito vinculado con la violencia.

Esta realidad se enfrenta con una fuerte tradición formalista jurídica que atraviesa al país, donde aquello que no esté soportado por una norma de producción estatal es considerado inefectivo, ineficiente, o incluso inexistente. Sin embargo, los debates académicos al respecto han demostrado la existencia de múltiples universos normativos que tienen efectos materiales en la vida de las comunidades que los construyeron, que son rápidos, eficaces, y sin ningún tipo de costo económico, como el del patio 4 de La Picota.

Con respecto a esta interpretación de la realidad social, es preciso aclarar que estos sistemas normativos, aunque no sean parte del derecho estatal, no necesariamente son opuestos a este; de hecho, muchos de ellos reproducen esas normas y formas jurídicas, e incluso algunos son reconocidos por el sistema jurídico formal. ${ }^{1}$ De la misma manera, es relevante precisar que no todas las expresiones de pluralismo jurídico son de naturaleza emancipatoria (Wolkmer, 2006), pues muchas de ellas administran justicia de formas violentas, bajo la ley del talión, como lo son las formas de regulación de conductas

1 En el marco de la Constitución Política de Colombia, la Ley Estatutaria 270 de 1996 incorpora la jurisdicción indígena como parte de la estructura de la rama judicial, dotándola de validez frente al ordenamiento jurídico estatal, aunque aquella existiera mucho antes que nuestro derecho occidental. en las mafias, el paramilitarismo o la mayoría de patios de la cárcel. ${ }^{2}$

En este orden de ideas, y con el ánimo de dotar al lector de herramientas para una mejor comprensión del fenómeno estudiado, a continuación se desarrollan ciertas premisas necesarias para abordarlo, las cuales se agrupan en cuatro componentes: 1) las que explican el problema de investigación, 2) las que justifican dicho problema, 3) las que fundamentan teóricamente el estudio, y 4) las que lo soportan conceptualmente.

Para comenzar, el problema de investigación se ubica en la crisis del sistema carcelario y penitenciario y su relación directa con la existencia de órdenes normativos, violentos y no violentos, que son creados por parte de los privados de la libertad para solventar la realidad que viven dentro de la cárcel.

El origen de esta crisis es posible ubicarla en la economización del poder estatal que ha degradado todas sus formas de control. Como señala Foucault (1969), la cárcel nace como un dispositivo secundario de control de la sociedad disciplinaria, que con el paso del tiempo se terminó convirtiendo en el principal; pero con la evolución del Estado moderno, el control social que tanto lo caracteriza mutó de igual manera. Así, el Estado actual es incapaz de "gestionar, dominar y controlar toda la serie de problemas, de conflictos, de luchas, tanto de orden económico como social" (Foucault, 1985, p. 2) y por ello desarrolla políticas, instituciones y aparatos tendientes a economizar su propio ejercicio del poder. Es la configuración de "un nuevo orden interior que obedece a una nueva economía" (1985, p. 2) la cual implica la redefinición de las misiones del Estado, retirándose del campo económico, reduciendo su papel social, y ampliando su intervención penal (Wacquant, 2010, p. 28). Sin embargo, a Colombia concretar el "Estado penal"3 le ha supuesto una tarea imposible.

2 Para profundizar en uno de estos ejemplos, es interesante revisar los estudios de Julio Rivera Clavería sobre Los Maras salvadoreños, donde señala lo altos niveles de control interno de sus integrantes a través de normas de comportamiento que son severamente sancionadas por los jefes de las clicas (Rivera, 2011).

3 "Lejos de contradecir el proyecto neoliberal de desregulación y extinción del sector público, el irresistible ascenso del Estado penal norteamericano constituye algo así como su negativo —en el sentido de reverso pero también de revelador-, porque traduce la puesta en vigencia de una política de criminalización de la miseria que es el complemento indispensable de la imposición del trabajo asalariado precario y mal pago como 
Para ilustrar la complejidad del problema (economizar su propio ejercicio de poder) en Colombia, es necesario dimensionarlo en su degradación en el tiempo, que puede rastrearse desde finales de la década de los noventa y comienzos del segundo milenio, cuando se realizó una reestructuración del sistema penitenciario. Los motivos de este rediseño se ubican en dos hechos principales que permiten entender la situación actual del sistema.

En primer lugar, el apoyo ofrecido por los Estados Unidos al país en el marco del Plan Colombia, que le permitió al Estado "retomar" el control de las cárceles que presentaban graves problemas de hacinamiento, poniendo como interés central la seguridad y dejando de lado la resocialización de los internos. Como señala el Instituto Rosarista de Acción Social -Seres- (2011), la principal evidencia de lo anterior son los nueve establecimientos construidos en ese periodo, con el apoyo y la dirección del Buró Federal de prisiones del Departamento de Justicia de los Estados Unidos, en convenio institucional con el INPEC.

En segundo lugar, la declaración de estado de cosas inconstitucional en las prisiones del país, hecha por de la Corte Constitucional en la Sentencia T-153 de 1998. Esta providencia es la mejor exposición de la realidad carcelaria en Colombia:

Las condiciones de vida en los penales colombianos vulneran evidentemente la dignidad de los penados y amenazan otros de sus derechos, tales como la vida y la integridad personal, su derecho a la familia [...] la situación descrita anteriormente tiende más bien a confirmar el lugar común acerca de que las cárceles son escuelas del crimen, generadoras de ocio, violencia y corrupción. (Corte Constitucional, Sentencia T-153, 1998, párr. 48)

Posteriormente, esta sentencia fue confirmada por la T-388 de 2013.

A partir de esta época se implementó en el país una política carcelaria alejada del deber estatal de garantizar la vida y la dignidad de las personas privadas de la libertad, que abandera la promoción de la seguridad y el orden, pasa por encima

obligación ciudadana, así como de la nueva configuración de los programas sociales en un sentido restrictivo y punitivo que le es concomitante" (Wacquant, 2010, p. 102). de los derechos inherentes a la persona humana y desdibuja por completo el fin último para lo que fue concebida la pena privativa de la libertad: resocializar ${ }^{4}$ o reinsertar en la sociedad (De la Cuesta Arzamendi, 1993).

En este orden de ideas, la cárcel hoy, como institución total (Goffman, 2001), reproduce todas las falencias del Estado: la violencia, la corrupción, la excesiva burocracia, las lógicas de la guerra, el narcotráfico, el racismo, la homofobia y la vulneración de derechos; siendo el reflejo del modelo penitenciario pensado y exportado para América Latina (Wacquant, 2010) propio de un paradigma de justicia retributiva ${ }^{5}$ que Colombia decidió heredar de Estados Unidos (Instituto Rosarista de Acción Social -Seres-, 2011).

De los mayores afectados de esta política carcelaria ha sido la comunidad LGBT que en ellas se encuentra, pues detrás de las rejas siguen siendo una población violentada y discriminada ${ }^{6}$ (Defensoría Delegada para la Política Criminal y Penitenciaria, 2009), a pesar de haber sido reconocidos como sujetos de especial protección constitucional. ${ }^{7}$

4 Diferentes autores le han dado denominaciones diferentes como "reeducación", "reinserción social", "reincorporación", pero en cualquier modo apunta a "asignar a la ejecución de las penas y medidas privativas de libertad una misma función correctora y aún de mejora del delincuente" (Muñoz Conde, 1979, p. 625).

5 Desde esta óptica, la pena debe ser acorde con la gravedad de la conducta criminal, pues considera que el dolor reivindicará la injusticia que se ha cometido; y deja de lado al victimario a la hora de recomponer el daño causado (Zehr, 2007).

6 El informe sobre la Situación de las personas identificadas como del colectivo LGBT privadas de la libertad en cárceles de Colombia (Defensoría Delegada para la Política Criminal y Penitenciaria, 2009) señala, entre muchas cosas, que: 1) hay diferentes grados de discriminación hacia personas LGBT, siendo más probable que los hombres pertenecientes al grupo trans del colectivo LGBT sean agredidos sexualmente por parte de otros internos; 2) en la gran mayoría de establecimientos carcelarios y penitenciarios no existe en el reglamento interno un capítulo especial para la visita conyugal del grupo LGBT, de hecho, hay dificultades en la implementación de la visita conyugal para el grupo LGBT; 3) Un gran número de directores, administrativos y personal de custodia y vigilancia no tiene conocimiento sobre la situación de las personas de la comunidad LGBT, persisten las creencias erróneas y se perpetúa el heterosexismo, la homofobia y el machismo.

7 La Corte Constitucional en la sentencia de estado de cosas inconstitucional T-388 de 2013 lo sustenta señalando que "las personas con orientaciones sexuales diversas son sometidas, aún, a tratos discriminatorios por parte de diversas personas de la sociedad. Estos prejuicios se reproducen en las cárceles y penitenciarias, siendo en muchas ocasiones, lugares donde estas prácticas y estos tratos se amplifican". 
Así, entendiendo la complejidad de este problema se evidencia la importancia de estudiar las dinámicas de regulación de conductas que crea la población privada de la libertad para sobrellevar las condiciones en las cuales se encuentran dentro de las prisiones y por ello surge el interés de identificar cuál es el justo comunitario de uno de los patios, de una de las cárceles más grandes del país.

El segundo componente de premisas para tener en cuenta son las razones que fundamentan el presente estudio; a saber:

- El lugar que este trabajo ocupa en la ciencia política, pues se parte de una valoración política de las dinámicas de la comunidad LGBT y la población privada de la libertad, en la medida en que el Justo Comunitario del Patio 4 es una disputa contra un orden hegemónico de violencia que caracteriza la cárcel colombiana, mediante una construcción comunitaria de normas que permiten la supervivencia pacífica intramuros.

- La pertinencia política de generar aportes, desde la academia, a la actual coyuntura de paz, que evidencien la necesidad de trasformación del sistema penitenciario y carcelario en Colombia, con miras a una cárcel para la paz que responda a las demandas de un nuevo país. Por ello, se hace imprescindible comprender la construcción de la paz como un eje transversal de todas las dimensiones de la vida; es decir, no como aquella que implica únicamente la dejación de armas y la eliminación de las violencias directas —en términos de Galtung (1976)—, sino también la superación de las violencias estructurales y simbólicas que garantizan la vida digna de todos los ciudadanos, incluso los privados de la libertad.

- El aporte a las políticas y decisiones concernientes a la cárcel en Colombia. Así, este estudio permite evidenciar una problemática social macro, que no ha sido tratada: la caducidad del actual sistema penitenciario y carcelario. Esta se ha traducido en las inhumanas e indignas condiciones en las que se encuentra la población privada de la libertad y las incontables violaciones a sus derechos fundamentales y humanos.

- La contribución a una discusión teórica en torno a este modelo penitenciario caduco, pues permite preguntarnos por la viabilidad de un paradigma de justicia retributiva que reproduce las dinámicas de violencia y conflictos dentro de las prisiones y la percepción social de los privados de la libertad como desviados que necesitan penas ejemplarizantes, dejando de lado las víctimas y la reparación del tejido social roto cada vez que se comete un delito.

- La importancia de este artículo para la población privada de la libertad. Sé que para ellos este estudio significa una posibilidad de visibilizar las dinámicas transformadoras que se generan al interior de la cárcel y que son desconocidas e ignoradas. Esto les permite evidenciar que sí es posible pensar un sistema carcelario diferente, que las lógicas de guerra no son el único camino a la hora de idear las políticas penitenciarias en Colombia.

Finalmente, la justificación metodológica. El estudio de caso de la comunidad LGBT sobresale por su idoneidad en dos dimensiones: 1) la primera refiere al porqué del estudio de caso como método y esto es porque permite lograr la comprensión holística necesaria para un caso complejo como el que he planteado, a partir de la descripción y el análisis detallado (Van Evera, 2002, pp. 63-64); y 2) la segunda es con respecto al porqué de la comunidad LGBT, y esto es porque son una población sobre la que recae no solo el peso de estar privada de la libertad, sino la discriminación en razón de su género, es decir, llevan sobre sus hombros dos ejercicios de poder para el control de sus cuerpos (Van Dijk, 1999, p. 26).

En tercera medida es preciso explicar el marco referencial teórico que acompañó todo el proceso de comprensión del fenómeno. Así, se produjo una intersección de tres aproximaciones teóricas: 1) una que refiere a la prisión, desde la teoría de las instituciones totales de Erving Goffman; 2) otra orientada al ordenamiento normativo que tiene lugar en el patio 4 de La Picota, a partir de la teorización de Antonio Carlos Wolkmer sobre el pluralismo jurídico comunitario; y 3) respecto al paradigma desde el cual parto para conocer e investigar fenómenos sociales, que fue fundamentado por la metaepistemología de Irene Vasilachis.

Para entrar a la teorización de las instituciones totales, hay que entender que estos estudios surgen de una corriente sociológica cuyo interés se ubica en las microestructuras sociales, es decir, en la cotidianidad, los encuentros, los contactos, las 
acciones de la vida social. Partiendo de esto, Erving Goffman centra su análisis en la interacción social, el entendimiento de la realidad desde los sentidos, las reglas e impresiones que organizan las interacciones sociales, y la multiplicidad de significaciones que pueden estar implicadas en nuestra experiencia del mundo bajo el concepto de frame.

Enmarcado en lo anterior, emerge el estudio de las instituciones totales para explicar aquellos "lugares de residencia y trabajo, donde un gran número de individuos, en igual situación, aislados de la sociedad por un período apreciable de tiempo, comparten en su encierro una rutina diaria administrada formalmente" (Goffman, 2001, p. 13). La cárcel es una de ellas, y está dotada de carácter totalizante en la medida en que crea un mundo propio para los internos — como él los denomina-, absorbiéndolos de tal manera que impide la interacción social con el exterior y genera mutilaciones del yo, es decir, de la subjetividad de los individuos internos.

En este orden de ideas, las cárceles son instituciones que, entre muchas cosas, se caracterizan por una multiplicación de reglas, que Goffman (2001, pp. 52-53) denomina normas de casa, ${ }^{8}$ activamente impuestas, conectadas con la obligación de realizar una actividad determinada; donde los "internos" no tienen más opción que someterse a estos reglamentos debido a la permanente interacción con las sanciones, que son emanadas del sistema autoritario y jerárquico de la prisión.

Sin embargo, a partir de las ideas de Goffman y la experiencia del trabajo de campo de este estudio dentro de La Picota fue posible dimensionar que posiblemente el mismo carácter totalizante de la prisión, que absorbe a sus integrantes y les proporciona un mundo propio, es paradójicamente lo que genera la existencia de comunidades y ordenamientos normativos alternativos al interior de ellas. Esto podría ser descrito, según lo evidenciado en el patio 4, como una suerte de artilugio que la población privada de la libertad genera para compensar una realidad que cualquiera, en esa situación, desearía forcluir ${ }^{9}{ }^{\text {esa }}$

8 Son uno de los elementos que constituye el sistema de privilegios que determina a las cárceles, y refieren al conjunto explícito y formal de prescripciones y proscripciones, que son recibidas a través de instrucciones formales e informales por el interno, para que ajuste sus conductas a ellas (Goffman, 2001, p. 58).

9 Tomaré prestado esta definición del psicoanálisis porque no hay otra palabra que logre nombrarlo. Forcluir es un término realidad es la imposibilidad de interacción social con el exterior, con sus familias, comunidades, colectividades, etc.

Por otra parte, es imprescindible situarse en la postura epistemológica de un pluralismo jurídico comunitario, que es aquel que "actúa en un espacio formado por fuerzas sociales y sujetos colectivos con identidad y autonomía propias, subsistiendo independientemente del control estatal" (Wolkmer, 2006, p. 1999). Es preciso entrar en tal detalle sobre cuál aproximación de pluralismo jurídico es la que tendrá lugar en el presente estudio, porque en las cárceles coexisten pluralismos normativos, pero solo serán las justicias de las comunidades que habitan dentro de la cárcel —no todo grupo social es una comunidad - la razón de ser de este esfuerzo.

Partiendo de la claridad anterior, es preciso identificar lo que Wolkmer (2006) denomina "las necesidades", que son un factor de producción de nuevos sistemas normativos y del que tiene lugar en el patio 4 de La Picota. Se trata de que los sujetos en una práctica cotidiana, determinada por una cultura, unas condiciones económicas, por la afectación a su dignidad y por el sofocamiento de la satisfacción a sus necesidades mínimas, configuran "nuevos agentes colectivos, que por voluntad propia o por la conciencia de sus intereses son capaces de crear e instituir nuevos derechos" (Wolkmer, 2006, p. 158), que serán soportados bajo sus propios universos normativos.

Finalmente, el presente estudio partió de un sujeto conocido supremamente humano, y con esto quiero referir que están atravesados por valores, prejuicios, mutilaciones del yo, identidades y vivencias, debido a los difíciles contextos económicos, políticos, sociales y culturales de donde la mayoría de la población privada de la libertad proviene (INPEC, 2017). Por esto, decidí ubicarme en una propuesta teóricometodológica que permita comprender de mejor manera el carácter o naturaleza que le atribuyen a la realidad social (Vasilachis, 2003, p. 26).

No siendo suficiente lo anterior, también partió de un sujeto cognoscente inconforme con lo que, desde los paradigmas hegemónicos de la investigación

tomado del derecho por Jacques Lacan, para referir al mecanismo a través del cual se produce un repudio o rechazo de algún contenido, expulsándolo por completo del universo simbólico del sujeto. 
en las ciencias sociales, se supone debe ser su rol. Intencionalmente me distancio de esos privilegios que "me corresponden" por ser la investigadora, y genero una ruptura con aquella relación predominantemente unidireccional, donde el investigador puede construir y transformar el sujeto estudiado, y además conservar la distancia necesaria para asegurar la objetividad (Vasilachis, 2003).

En este orden de ideas, decidí hacer el presente estudio desde este marco epistemológico y metodológico a partir del cual "la epistemología del sujeto conocido viene a complementar la epistemología del sujeto cognoscente sin excluirla" (Vasilachis, 2003, p. 25). Es una propuesta por una construcción cooperativa de la realidad.

Para Irene Vasilachis (2003), esto parte de cuatro supuestos básicos, que comparto plenamente: 1) la resistencia a la naturalización del mundo social, es decir, la no búsqueda de causalidad, generalizaciones y predicciones asociadas al mundo físico; 2) la relevancia del concepto de mundo de la vida, es decir, este mundo que constituye el contexto en el que se dan los procesos de entendimiento y proporciona los recursos para la acción; 3) el paso de la observación a la comprensión y del punto de vista externo al punto de vista interno, es decir, entender la realidad de cada contexto simbólicamente reestructurada, implicando una función participativa del intérprete que no otorga significados a lo observado sino que hace explícita la significación dada por los participantes; y 4) la doble hermenéutica, es decir, los conceptos de segundo grado que crean los investigadores para interpretar una situación que ya es significativa para los participantes, pero que a su vez son utilizados por los individuos para interpretar su situación, convirtiéndolos en nociones de primer grado.

Entonces, a modo de síntesis, es posible entender cómo esa nueva vida, ese universo propio que empieza a construir la cárcel, como institución total, puede generar comunidades o mafias, complicidades, carteles, asociaciones; que generan interacciones sociales específicas en torno a las dinámicas de la convivencia, como lo es la administración de su propia justicia. La metaepistemología será la que guiará la aprehensión de esto.

El cuarto bloque de premisas refiere al marco referencial conceptual, es decir, adentrarse a los conceptos propios de cada aproximación teórica desarrollada anteriormente para aplicarlos al alcance de los objetivos. En este orden de ideas serán explicados los conceptos de prisionalización, normas de casa, comunidad, justo comunitario, método científico tradicional, población privada de la libertad, y comunidad LGBT.

Para comprender las instituciones totales es importante el manejo de dos conceptos claves que orbitan alrededor de la teoría. La prisionalización es la asimilación por los internos de las costumbres y valores carcelarios comunes que configuran la cultura de la prisión (Clemmer Donald, 1940); es decir, es un efecto directo del carácter totalizante de la cárcel. Este se configura como un proceso mediante el cual los comportamientos de la población privada de la libertad son moldeados por las características sociales, y sobre todo estructurales, de la vida en prisión.

Esta cultura de la prisión es lo que Goffman (2001, p. 58) denomina normas de casa, que refiere al conjunto explícito y formal de prescripciones y proscripciones, que son recibidas a través de instrucciones formales e informales por el interno, para que ajuste sus conductas a ellas. Su reproducción, su repetición diaria, su ritualización, es la que es interiorizada por la población privada de la libertad, y la que construye un nuevo mundo intramuros con nuevas normas de interacción social.

Entonces, estas categorías conceptuales permiten comprender la relación directa entre las crisis del sistema penitenciario y carcelario colombiano, que ha edificado unas condiciones indignas para la población que habita las cárceles, y las relaciones violentas que se reproducen al interior, e incluso las resistencias a esas dinámicas como pasa en el patio 4 de La Picota.

Ahora bien, para ubicar el lugar del pluralismo jurídico comunitario en el presente estudio ${ }^{10}$, es importante conocer lo que se entiende por comunidad, pues esta soportará teóricamente la premisa de que en las cárceles hay comunidades, y por tanto ellas pueden generar también sistemas normativos de

10 Antonio Carlos Wolkmer hace todo su análisis del pluralismo jurídico comunitario a partir de los movimientos sociales, entonces se podría llegar a concluir que las comunidades que habitan en los centros penitenciarios no son compatibles con esta teoría. 
corte democráticos como los pluralismos jurídicos comunitarios.

Ferdinand Tönnies (1957), afirma que hay comunidad cuando existe una pertenencia, un sentimiento que hace a un grupo humano entenderse como un conjunto, es decir, cuando hay una identidad mediando las relaciones. Entonces, considera que la comunidad se edifica a través de tres tipos de relaciones sociales: el parentesco, la vecindad y la amistad; siendo estas tres las formas bajo las cuales se construye una identidad.

Así, el parentesco es la relación de afecto y protección entre unos individuos, determinando las normas entre ellos; la vecindad es la referente a la convivencia que implica la proximidad entre las viviendas, los bienes comunales o simplemente la contigüidad de los campos, estando altamente determinada por la costumbre; y finalmente la amistad, que es la que tiene menor carácter orgánico, que es menos instintiva, y que puede surgir sencillamente por simpatía, casualidad o libre elección (Tonnïes, 1947, pp. 33-34). En las cárceles pueden existir perfectamente los tres tipos de relación, o incluso relaciones que podrían ser mixturas de las mismas.

Con todo esto el autor establece una idea de comunidad que:

se origina gracias a las relaciones que pueden establecerse entre las personas, aún desde la diversidad. Esas relaciones son armónicas porque se soportan en el común sentimiento de pertenecer a lo mismo, porque cada uno siente que los otros se comportan (comen, se visten, se casan, se emparentan, hacen negocios, participan) bajo la misma estructura normativa (tradicional, religiosa, ética, estética). Para Tönnies existe una relación estrecha entre comunidad y norma social. (Ardila, 2006, p. 152)

En este orden de ideas, fue posible entender que existen comunidades en las cárceles, que estas tejen normas al interior de ellas, y que, en ese sentido, configuran algún nivel de justicia comunitaria, entendida esta como un conjunto de concepciones e imperativos de una comunidad que soportan unas prácticas justiciables (UMSS, 2009, p. 2), es decir, una forma de administrar justicia a través de estructuras normativas propias de la comunidad, derivadas del justo comunitario (Ardila, 2006, p. 147).
Por lo desarrollado hasta acá es posible hacer uso de categorías como el justo comunitario, es decir, todo lo que configura la idea de justicia en una comunidad. Este concepto es nuevo dentro de los estudios del pluralismo jurídico, pero tiene sus raíces en lo que desde la sociología y la antropología se conoce como "norma social" (Ardila, 2006). Así, resumiendo a grandes rasgos la relación entre estos dos conceptos es posible aseverar que la norma social se convierte en justo comunitario solo cuando la comunidad necesita administrar justicia, pues no todas las normas sociales existen para este fin. ${ }^{11}$

Entonces, para comprender de mejor manera es preciso recurrir a la magistral descripción de Espinoza (2010):

es el criterio normativo fundamental del que se derivan - en consecuencia- las normas de convivencia de las comunidades; es bajo este criterio que las acciones jurídicas [...] se asumen como legítimas o no por las comunidades. Es en suma el máximo criterio que define cuándo hay o no conflictos, sobre éste se reconoce la justicia de los procedimientos para la resolución de los problemas, así como la justicia en la solución a que da lugar. De igual forma, el justo comunitario previene futuros conflictos al fijar los lineamientos de acción, transacción y negociación que deben seguir los campesinos. Lo justo es el principio moral que legitima y fundamenta las actuaciones, decisiones, normas y leyes de la justicia local, pues dicho criterio le da validez a cada uno de ellos. (Espinosa, 2010, p. 16)

Se evidencia entonces que, desde esta visión, el marco de decisión ya no es la ley (Ardila, s.f., p. 18), como socialmente se cree que es lo que garantiza la justicia, sino el criterio "lo justo" (Espinosa, 2010, p. 15) construido por una comunidad a través de prácticas atravesadas por principios morales que se convierten en fundamentos normativos. Esto último será el resultado final de este estudio.

Por su parte, en torno a la elección del paradigma para la investigación de fenómenos sociales

11 Es de recordar que administrar justicia, en este caso, no refiere al arbitrio de los órganos del Estado, ya que "las normas sociales existen de manera autónoma frente al Derecho porque regulan los comportamientos de sujetos diferentes" (Ardila, 2006, p. 79). 
propuesto por Irene Vasilachis (2003) denominado metaepistemología, es menester reconocer los elementos del método científico tradicional que van en contravía con este estudio. Así, este método científico en las ciencias sociales es aquel que debe dar cuenta objetivamente de los resultados hallados, debe probar resultados con "evidencias" obtenidas de acuerdo con la ciencia y debe estar elaborado bajo un razonamiento lógico deductivo. Para que lo anterior sea posible los sujetos son considerados objetos, un "algo" cuyo rol es permitir ser observado por unos sujetos que, a partir de un marco teórico unívoco, darán con la razón y la verdad de lo que ven, generando una relación jerárquica de poder entre el investigador y el objeto. Así, el método científico tradicional se encarga de limitar el alcance de los hallazgos y reduce la realidad social a sus categorías (Vasilachis, 2003, p. 26).

Este estudio evitó a toda costa dichos limitantes y partió de la interacción entre ambos sujetos —el sujeto conocido y el sujeto cognoscente- como iguales, en donde ambos teníamos la capacidad de conocer.

Con respecto al uso de la denominación población privada de la libertad, fue una elección que es considerada consecuente con el marco teórico escogido en el presente estudio. Según la teorización de las instituciones totales, internos son los que viven dentro de la institución, aislados del resto de la sociedad. Entonces, las instituciones totales levantan barreras entre el interno y el externo, que marcan en ellos la primera mutilación del yo (Goffman, 2001, p. 27), es decir, es el primer despojo de la subjetividad que recibe una persona tan pronto entra a la cárcel. Llamarlos presos o internos es reproducir las lógicas de las instituciones totales por quienes no hacemos parte de ellas, por quienes representamos "el mundo exterior" para ellos.

La última categoría, comunidad LGBT, es utilizada comúnmente con el objetivo de hacer referencia a quienes me permitieron hacer un estudio de caso y conocer a fondo el patio 4 de La Picota. Para efectos del presente trabajo prescindiremos de los debates que existen alrededor de las siglas desde las diferentes corrientes teóricas del género, pues sencillamente así se autodenominan las personas recluidas que se reconocen con una identidad de género $u$ orientación sexual diversa ${ }^{12}$ (Red Comunitaria Trans, 2015), y sin lugar a duda, merecen ser nombradas bajo su consideración.

Finalmente, como el lector ya se habrá percatado, a lo largo de este estudio utilizo un estilo narrativo que permite voces en primera persona, con el ánimo de facilitar la emergencia de los otros en el escrito debido a su importancia en la realización de los objetivos políticos y teóricos expuestos ${ }^{13}$.

\section{METODOLOGÍA}

A continuación, explicaré la estructuración metodológica del presente estudio, la cual se hizo desde un abordaje de la investigación cualitativa no experimental, procurando acceder desde adentro a la estructura de significado propias de la situación de privación de la libertad, a fin de captar el sentido de la acción social en el contexto del mundo de la vida intramuros.

La elección de la metodología cualitativa supone renunciar a la construcción de definiciones normativas y se caracteriza por subrayar la naturaleza socialmente construida de la realidad social, poniendo énfasis en la interpretación de los fenómenos sociales que los mismos actores le dan (Vasilachis, 2003, pp. 50-52). Por ello será el marco metodológico que acompañará cuatro métodos implementados y las respectivas técnicas que los hicieron posibles.

\section{Métodos}

Teniendo en cuenta la necesidad de entender un fenómeno social de alta complejidad como lo es la justicia comunitaria en la cárcel, y partiendo de limitantes propias de investigar dentro de la cárcel, se usaron cuatro métodos, el estudio de caso, la entrevista dialogada, la encuesta y análisis documental; esperando que juntos permitieran la mayor aproximación posible al objeto de estudio.

Para lograr con éxito los objetivos planteados, el método principal utilizado fue el estudio de caso. Fue considerado como una aproximación válida

12 La sigla representa a las personas lesbianas, gay, bisexuales y transgénero.

13 Esta aclaración se debe a que es imperativo en el método científico usar los recursos lingüísticos de redactar de forma impersonal, pues es la adecuada presentación de un texto científico en las ciencias sociales (Vasilachis, 2003). 
en la media en que, para realizarlo, requiere de un contacto, sin ningún tipo de mediación, con el sujeto conocido (Gómez-Peresmitré y Reidl, 2016), que en la especificidad de este estudio fue la comunidad LGBT privada de la libertad, en su espacio natural, el patio 4 de la estructura 1 del Comeb.

Así, este método consiste en que, de un ejemplo considerado como un todo en su contexto, se pueda lograr la comprensión holística de la complejidad de dicho fenómeno, a partir de una descripción y un análisis muy detallado. Es pertinente para detectar las características más representativas, en este caso, del justo comunitario del pabellón 4 del complejo carcelario y penitenciario metropolitano de Bogotá "COMEB", La Picota, en el año 2017, capturando la evidencia que permitió verificar las predicciones (Van Evera, 2002, pp. 63-64) que en alguna medida se esbozaron en el marco teórico.

De manera complementaria, se utilizaron otros métodos de carácter cualitativo y cuantitativo, que fueron exitosos para producir información sobre el caso. Así, se acudió a la entrevista dialogada, que permitió captar la producción de un lenguaje natural; determinar las características que asumen los procesos de construcción de identidad en los relatos de vida y el significado que los actores otorgan a la acción de otros y la suya, y reconocer "la participación activa y reflexiva del sujeto conocido en la interacción cognitiva" (Vasilachis, 2003, p. 51).

De la misma manera se usó la encuesta, debido a que es idónea para la recolección de datos, aunque se suela usar principalmente desde análisis cuantitativos (2008, p. 8). Fue de gran importancia el uso de esta modalidad de estudio pues permitió cuantificar cierta información relevante, y en ese sentido poder establecer, con mayor fuerza, algunas constantes - no generalizaciones - dentro de las percepciones de la población privada de la libertad.

Finalmente, el registro documental en archivos manuales y digitales fue fundamental para la recolección de datos cualitativos o cuantitativos (Macluf Escudero, Delfín Beltrán y Gutiérrez González, 2008 , p. 8) que eran importantes de precisar para este estudio.

\section{Técnica}

Para comenzar, es preciso mencionar las dificultades técnicas que presenta un estudio que tiene la cárcel como locación. Los ingresos son complicados, incluso en la estructura de mínima seguridad, y solo se me permitió tener contacto con aquellos que están en los pasillos, es decir, a quienes les falta poco tiempo para quedar en libertad.

\section{Estudio de caso}

Quien hizo posible el estudio de la comunidad LGBT fue un investigador del grupo de investigación al que hago parte, la Escuela de Justicia Comunitaria de la Universidad Nacional de Colombia (EJCUN), que a su vez es exguardia del INPEC $y$ ha coordinado diferentes proyectos de investigación e intervención en diferentes centros penitenciarios.

A través de él pude tener contacto con otros guardias que actualmente están trabajando en el Comeb, quienes me facilitaron la entrada y el contacto con Sebastián.

Así, en el primer semestre de trabajo de campo organicé visitas a la estructura 1 de La Picota, llegando desde temprano en las mañanas para iniciar las gestiones burocráticas pertinentes con el fin de que me autorizaran el ingreso. En varias ocasiones me fue negado "porque se hacía muy tarde", "porque no estaba tal persona", o porque sencillamente no tenían la disposición de dejarme entrar.

Así mismo, partiendo de los conocimientos adquiridos en la EJCUN, pude conocer el contexto de una cárcel como La Picota y las actividades típicas del diario vivir de las personas privadas de la libertad, que facilitaron la construcción del instrumento de la encuesta.

\section{La entrevista dialogada}

Teniendo en cuenta lo anterior, la entrevista dialogada fue realizada, bajo consentimiento informado, a Sebastián, ${ }^{14}$ un gay cartagenero que estaba en la cárcel por hurto simple y que además era representante de derechos humanos por parte de la comunidad LGBT de la estructura 1, que es la de mínima seguridad. Es sumamente charlador y diligente, fue quien me acompañó durante todo el proceso investigativo, quien me presentó ante la comunidad LGBT e hizo posible la toma de las

14 Seudónimo elegido, pues el entrevistado no deseó que se conociera su identidad. 
encuestas y demás observaciones que necesitara. La elección de hacerle la entrevista a él fue por decisión y voluntad propia, que él expresó tan pronto le conté mis intenciones.

Como entrevistadora, presuponiendo la igualdad entre ambos, inicié con una presentación mía, abriendo mi identidad personal plenamente, contándole mi proveniencia, mis intereses, dónde estudio, por qué estudiaba lo que estudiaba; y a partir de esto, en la biblioteca, se construyó una conversación bastante elocuente que nos permitió compartir saberes el uno con el otro. Se podría describir como una situación de participación y reflexión del sujeto conocido en la interacción cognitiva, que se caracterizó por la validez de los conocimientos y las formas en que Sebastián interpretaba la realidad.

Fue muy espontáneo, y comprendió fácilmente las preconcepciones que yo le iba contando que tenía con respecto a la cárcel, las cuales me cuestionaba una y otra vez a lo largo de la entrevista.

Finalmente, tuvimos que cortar la entrevista porque ya se me terminaba el tiempo del permiso de entrada.

\section{La encuesta}

Realicé la encuesta a través de un muestreo no probabilístico por conveniencia (Otzen y Manterola, 2017), es decir, la selección de los sujetos que fueron encuestados fue determinada por quienes estuvieran disponibles en el momento de ingreso a la estructura 1 de La Picota, esto es, por quienes estuvieran en los pasillos en ese momento; aplicando un filtro con dos criterios: 1) que fueran de la comunidad LGBT; y 2) que hicieran parte del patio 4.

La encuesta se realizó en las instalaciones de la biblioteca, bajo la observación de un guardia del INPEC que me fue asignado para que me acompañara en la aplicación del instrumento construido para dichos fines.

Tenía el temor de que al ser un instrumento relativamente largo no iba a ser llenado por ellos, a lo cual me respondieron que era mucho mejor, pues tienen demasiado tiempo libre y esto los sacaba un poco de su rutina.

Finalmente, es importante mencionar que uno de los encuestados estaba aprendiendo a leer hasta ahora, y me pidió el favor de asistirle la lectura para que pudiera responder a cabalidad el instrumento.

\section{El análisis documental}

Fue un método transversal del presente estudio, que consistió en una búsqueda constante de documentos físicos y digitales que me permitieran recopilar información cuantitativa y cualitativa del fenómeno de estudio. Logré sortear el manejo de tanta información a través de la elaboración de fichas de Resumen Analítico Especializado (RAE) de aquellos documentos que fueron seleccionados para analizar o conocer el fenómeno social de pluralismos jurídicos en la cárcel.

\section{RESULTADOS Y DISCUSIÓN}

\section{Estado de convivencia del pabellón 4 del complejo carcelario y penitenciario metropolitano de Bogotá "Comeb" —La Picota— en el año 2017}

A lo largo del presente estudio fueron desmitificadas muchas preconcepciones y la primera de ellas fue pensar la cárcel de manera unívoca, como si los que estuvieran dentro de esa infraestructura fueran un todo homogéneo. En este sentido, cada patio, de cada estructura, de cada centro penitenciario tiene dinámicas completamente diferentes, como por ejemplo el caso particular del pabellón 4 de La Picota.

Si se tratara únicamente de responder a la pregunta por el estado de convivencia de este patio, la sistematización de la información apunta a que los privados de la libertad pueden convivir sin mayores conflictos en este patio - cosa que no sucede en los otros patios, como ellos señalan-; pero los matices permiten mayor margen de entendimiento y comprensión del fenómeno, y por ello detallar las diferentes situaciones que configuran la convivencia del pabellón se ajusta más a mis pretensiones investigativas, y a las de ellos de dar a conocer lo que viven dentro de los muros.

A partir de la encuesta se logró sistematizar la percepción de conflictividad de la población privada de la libertad con respecto a una lista de situaciones propias de su diario vivir. A continuación, me referiré a las cuatro situaciones que fueron manifestadas como las más conflictivas, que son el mantenimiento 
del aseo general del patio, los momentos de "la contada"15, el uso del expendio ${ }^{16}$ y la alimentación, acompañada de una breve explicación de estas desde lo desarrollado en la entrevista dialogada.

En el mantenimiento del aseo general: Se generan discusiones entre los privados de la libertad porque es una tarea que desean terminar pronto los que la tienen encargada y los demás se demoran en dejarles los espacios para poderlo hacer. Así, un ejemplo muy típico contado por Sebastián es el del domingo "porque es día de visita y todos queremos entrar a bañarnos, entonces que por qué se demora, que por qué no se rasuró ayer, que cinco minutos, que ya se pasó el tiempo, porque todos queremos estar bonitos para nuestras visitas y eso que acá comienzan duchas desde las 3 de la mañana, imagínate". (Sebastián, comunicación personal, 27 de noviembre de 2017).

Lamentablemente, estas situaciones a veces escalan en violencia. Sin embargo, es preciso señalar que la justicia comunitaria no tiene, ni debe tener, la misma pretensión del derecho occidental moderno de acabar con los conflictos, sino que, por el contrario, se edifica sobre la premisa de que las relaciones sociales son conflictivas, y que en estas se pueden presentar tanto situaciones sencillas de incompatibilidad de intereses inmediatos como otras de corte más estructural en las que normas sociales, valores y creencias se encuentran en contradicción. A pesar de esto, de lo que se debe tratar es de la gestión y transformación de los conflictos, evitando el escalamiento a hechos violentos, que generen la destrucción de tejidos sociales.

En la contada: Al menos tres veces al día la guardia cuenta a todos los privados de la libertad, siendo una actividad que implica una formación en filas de cinco personas. Si el guardia empieza a contar y llega a una fila que no está lista porque le falta formar al menos a una de las cinco personas, debe volver a contarlos desde el comienzo; "entonces pues los demás se ponen rabones y empiezan a gritarle a los demorados, porque queremos que la

15 Es el proceso mediante el cual se cuentan a las personas privadas de la libertad de cada patio.

16 Es el lugar donde los privados de la libertad adquieren productos de uso o consumo cotidiano con el dinero que les consignan sus familias. Es de aclarar que ellos no manejan dinero, sino que es consignado a nombre del beneficiario a una cuenta que tiene cada establecimiento penitenciario. guardia se vaya rápido. (Sebastián, comunicación personal, 27 de noviembre de 2017).

Generalmente la guardia de la estructura uno de La Picota está en los pasillos de los patios, cuidando puertas o acompañando a los privados de la libertad que trabajan hacer sus labores; por ello cuando la guardia entra se genera una molestia, pues esta visita puede traducirse en requisas, maltratos, o sencillamente en la percepción de una irrupción de la tranquilidad.

En el uso del expendio: Es cuando los privados de la libertad adquieren sus útiles de aseo, y demás cosas que necesiten. En esto suelen suceder conflictos menores, principalmente por el orden en la fila. Cuenta Sebastián que "pues uno le grita imire a ver si respeta la fila!, iubíquese bien! y ya, normalmente se soluciona hablando. (Sebastián, comunicación personal, 27 de noviembre de 2017).

Suele ser una situación tensionante, además, porque el expendio suele funcionar hasta agotar existencias, entonces no hay un surtido permanente que les permita pensar que no tiene sentido colarse en la fila.

En la alimentación: Principalmente se generan conflictos por la calidad de la comida. Comenta Sebastián entre risas que "la comida es gas, pero gracias a Dios la hay; y pues los demás se molestan porque no sirven un buen menú. Eso también es responsabilidad de nosotros mismos, de la gente que está en el rancho y que no cocinó una buena comida. Lo hacen por salir del paso. (Sebastián, comunicación personal, 27 de noviembre de 2017)

Adicionalmente, ir al comedor es la posibilidad de encuentro con otros que no son del patio, entonces se presta para algún nivel de desorden que la guardia no tolera.

Es preciso señalar que frente a todas las actividades que componen el diario vivir de los privados de la libertad, de manera unánime opinaron los entrevistados de la comunidad LGBT que los conflictos se resuelven dialogando; con excepciones en la alimentación y el mantenimiento del aseo general, que eventualmente terminan en violencia, en gran medida porque son momentos de encuentro con privados de la libertad de otros patios.

Las anteriores actividades son unas de las tantas normas de casa (Goffman, 2001) que los privados 
de la libertad deben hacer en su diario vivir, y la repetición diaria de estas y sus reiterativas sanciones en caso de incumplimiento van condicionándolos a una nueva forma de relacionarse e interactuar. Como se había señalado en la introducción, esta es una de las característica principales de las instituciones totales y su consecuencia directa es el fenómeno de prisionalización (Clemmer Donald, 1940), es decir, la asimilación de las costumbres y valores carcelarios comunes por parte de todos aquellos que habitan la cárcel.

Los privados de la libertad que hacen parte del patio 4 también se encuentran inmersos en las lógicas que se acaban de mencionar, sin embargo, han logrado su no reproducción interna en el pabellón, donde de cierta forma pueden convivir bajo unas reglas paralelas que son las que les permiten tener tal nivel de convivencia pacífica. Estas normas serán señaladas más adelante.

\section{Mecanismos de resolución de conflictos del pabellón 4, estructura 1, del complejo carcelario y penitenciario metropolitano de Bogotá "Comeb" — La Picota-}

Quizá fue este uno de los aspectos más sencillos de ubicar porque en las encuestas los resultados frente a este punto fueron unánimes y la entrevista complementó de sobremanera esta información. Para caracterizar los mecanismos de resolución de conflictos del patio 4 fue preciso identificar la forma usual de tramitarlos, los actores claves en dicha gestión, los procedimientos que manejan y las sanciones establecidas.

En primera medida, los datos obtenidos a partir de los métodos del estudio afirman que las formas más comunes para solucionar un conflicto dentro del patio son a través de diálogo tratando de resolverlo de forma inmediata y pidiéndole a un compañero ideas de solución.

Así mismo, a la hora de hablar de los actores que intervienen en la tramitación de conflictos, unánimemente consideraron los privados de la libertad que el líder del patio es la persona que más participa en la resolución conflictos, además es quien los resuelve de manera más efectiva y siempre que se presentan acostumbra emplear el diálogo.
Es preciso mencionar en este punto que el líder del patio 4 no es un individuo, como suele suceder normalmente en los patios de las cárceles colombianas, al cual le llaman "pluma" o "cacique"; sino que es un grupo de personas que se denominan "la dirección". Este particular fenómeno es lo que explica en gran medida las características inverosímiles del patio 4 , en lo que respecta a la justicia comunitaria que allí se ejerce, y por ello considero necesario que sea leído a través de los fragmentos de la entrevista con Sebastián, pues ilustran de manera magistral la autoridad del patio:

La dirección es la pluma, el cacique, solo que en el patio cuatro se llama la dirección, así se decidieron llamar. Son seis personas que toman decisiones con respecto a las normas del patio. Para ser de la dirección hay que ser un preso político, o sea los de las FARC, y segundo, hay que ser respetado y hacer respetar las normas. (Sebastián, comunicación personal, 27 de noviembre de 2017)

La dirección tiene establecido un procedimiento generalizado para la solución de controversias dentro del patio, o para el establecimiento de prohibiciones o nuevas normas, el cual se podría resumir en una serie de deliberaciones colectivas, que pueden tomarles mucho tiempo. Sin embargo, todos me comentaban que adentro les sobra tiempo, y por ello, no les importa cuánto tarden estas dinámicas. En palabras de Sebastián:

[...] Son seis personas que toman decisiones sobre la convivencia del patio, luego esa decisión se la comunican a todo el patio, hacemos una reunión donde todos discutimos con qué cosas estamos de acuerdo y con qué cosas no estamos de acuerdo y con eso otra vez vuelve y se reúne la dirección y vuelven y nos comunican y así sucesivamente; entonces pues siempre hay debate y las decisiones se toman entre todos. (Sebastián, comunicación personal, 27 de noviembre de 2017)

Finalmente, como última instancia están las sanciones que son impuestas desde la dirección a aquellos que han quebrantado alguna norma social o que no hayan cumplido con sus obligaciones. Este es otro de los aspectos particulares que diferencia al patio 4 con otros cuyas lógicas son marcadamente violentas. Así, en dichas situaciones se interpone 
una queja con la dirección para que dé trámite a dicha penalización:

¿Qué con quién ponemos la queja? Mija, pues la ponemos con la dirección y ellos le ponen alguna sanción a la persona que no pague la deuda, por ejemplo, en mi patio siempre se pone una sanción de aseo.

[...] Yo sé que las cosas en todos los patios no son así. Las sanciones son dando cachaza, todo el tiempo te golpean por todo, y puedes meter bazuca, perico, mariguana, pepas, todo lo que quieras en todos los lugares. Pero acá no. (Sebastián, comunicación personal, 27 de noviembre de 2017)

Hasta acá, fue posible identificar que el mecanismo por excelencia para tramitar los conflictos es el diálogo entre las partes, pero si por alguna razón este mecanismo no funciona, el líder del patio, es decir, la dirección del patio 4, es el máximo órgano de gestión, tramitación y decisión en los conflictos e impartición de sanciones. Es preciso resaltar que cuentan con absoluta legitimidad dentro del patio, la cual en gran medida se desprende de la verticalidad militar de la que provienen los exguerrilleros, pero así mismo de la práctica y ejemplo que ellos evocan dotándolos de suma autoridad, incluso entre aquellos que no fueron de las FARC-EP, por ejemplo, la comunidad LGBT que con ellos habita.

Esto permite reafirmar que es un pluralismo jurídico comunitario (Wolkmer, 2006) el que tiene lugar en el patio 4, de la estructura 1 de La Picota, cuya fuente de existencia se explica por la necesidad de dar respuesta a la permanente insatisfacción de múltiples derechos, que es a lo que están condenados por el actual sistema penitenciario en Colombia.

La comunidad LGBT tiene una necesidad puntual de seguridad, bienestar e incluso de supervivencia intramuros, que no es garantizada por el INPEC y por ello se acogen a una autoridad que hace parte de otro sistema normativo.

Además de esto, lo desarrollado en este acápite reviste de carácter "comunitario", la expresión de pluralismo jurídico del patio 4 de La Picota. Es evidente que son comunidad (Tonnïes, 1957) en la medida en que existe algún nivel identitario mediando las relaciones sociales existentes allí, que no se expresa en una identidad homogénea de presos políticos, exguerrilleros o revolucionarios, pero sí, desde su diversidad, se consideran un grupo de personas diferentes al resto de la cárcel, que tienen en común la creencia en valores democráticos, en la no discriminación, en el rechazo a la deshumanización a la que se les condena, en proyectos políticos a favor de los vulnerados y en la necesidad de cuidarse entre ellos.

\section{El justo comunitario del pabellón 4 del complejo carcelario y penitenciario metropolitano de Bogotá "Comeb" — La Picota-}

Este fue, sin lugar a duda, el hallazgo más importante que este estudio desmitificó: isí existen en las cárceles dinámicas de justicia y regulación de conflictos que no se basan necesariamente en el uso de la violencia, y que por el contrario funcionan bajo algún nivel de democracia!, lo que permite reafirmar la idoneidad del pluralismo jurídico comunitario como aproximación teórica al sujeto de estudio.

La inverosímil sistematicidad con la que se han construido las normas sociales que edifican la convivencia del patio 4 puede ser ilustrada y resumida en los siguientes seis "mandamientos":

1. Prohibida la discriminación.

2. Prohibido el uso de sustancias psicoactivas.

3. Prohibida la venta de medicamentos.

4. Prohibido el escobeo.

5. Prohibido tener preferencias entre las personas.

6. Educación permanente con asistencia libre.

El primero es uno de los más importantes para la comunidad LGBT porque la discriminación, en sus múltiples expresiones, es a lo que comúnmente se tienen que enfrentar, comprende su diario vivir en la cárcel. "Entonces la primera norma es el respeto, ante todo, entre todos; está prohibida la discriminación. Por eso la comunidad LGBT normalmente pide cambio de patio al patio cuatro, porque ahí sí nos respetan, no nos tratan mal, no nos golpean ni nos discriminan" (Sebastián, comunicación personal, 27 de noviembre de 2017). 
Es de tal nivel la discriminación que ellos sufren intramuros que Sebastián se vio en la necesidad de narrarme cómo llegó al patio 4, tras numerosas situaciones de violencia contra él en razón de su género, para que yo pudiera dimensionar la gravedad de las cosas:

Es que te cuento, cuando yo recién llegué a la cárcel hace tres años, llegué al patio uno. De una cuando llegué yo no quise contar que era de la comunidad, pero mi primer día de visita vino mi novio y entonces todos en el patio se dieron cuenta de que era marica. Desde ese momento me empezaron a discriminar, ese mismo día el pluma me sacó a dormir al pasillo, incluso a pesar de que yo había pagado mi espacio de celda, y ahí adelante me empezaron a tratar mal, a golpearme, me robaban y al final pluma dijo que solicitara cambio de patio porque en ese no iban aceptar a ninguna partida. (Sebastián, comunicación personal, 27 de noviembre de 2017)

Efectivamente Sebastián tuvo que solicitar un cambio de patio y nuevamente fue víctima de malos tratos, pues los demás privados de la libertad le advirtieron que no podía entrar por ser homosexual:

[...] me pasaron al patio tres, que es donde están la mayoría de los ladrones, y decidí que no iba entrar al patio y empecé a vivir y a dormir ahí en el pasillo para que no me maltrataran. Después de una semana ya me habían robado todas las cosas, hasta los calzoncillos. (Sebastián, comunicación personal, 27 de noviembre de 2017)

Sin embargo, por ser homosexual el pluma del patio tres decidió aceptarlo, aunque si hubiese sido trans seguramente su suerte hubiese sido otra. Entonces

[...] me acuerdo muy bien de estas palabras (risas), pues como yo no vestía de mujer me dijo: coja sus cosas, lo poquito que le dejaron, y váyase a dormir al patio, no se te nota ningún quiebre, ninguna mariquera. (Sebastián, comunicación personal, 27 de noviembre de 2017)

Unos meses después Sebastián tomó la decisión de solicitar cambio al patio cuatro, y desde entonces lo habita, seguro de haber sido una de las mejores decisiones que ha tomado en mucho tiempo: “[...] acá no me han tratado mal ni una sola vez. Todo el tiempo la dirección es diciéndole a todos que no se metan con las niñas, que las niñas se respetan, refiriéndose a los de la comunidad" (Sebastián, comunicación personal, 27 de noviembre de 2017).

La segunda regla refiere a la prohibición del uso de sustancias psicoactivas y a la regulación del consumo exclusivo de marihuana en lugares delimitados por la dirección:

[...] en nuestro patio no se permite a ningún vicioso. Solo se permite el consumo de mariguana en una zona en específica para fumarla. Queda en un pasillito, entre la cancha y los baños, y ahí hay como una línea imaginaria de la cual uno no se puede pasar porque si tú te pasas fumando mariguana, te sancionan. (Sebastián, comunicación personal, 27 de noviembre de 2017)

Como consecuencia de la anterior, está prohibido también la venta de medicamentos, que parece ser una práctica bastante cotidiana en la cárcel. Sebastián me comenta que

[...] cuando a uno le duele la cabeza o tiene algún malestar le dan medicamentos a uno y autorizan el consumo de ibuprofeno o acetaminofén, entonces lo que hacen normalmente los de otros patios es vender esos medicamentos, porque necesitan la plata para el consumo, la bazuca, las pepas. Y eso no está permitido dentro del patio cuatro. (Sebastián, comunicación personal, 27 de noviembre de 2017)

Como cuarta norma se encuentra la prohibición del escobeo, es decir, el robo, la cual es considerada una conducta bastante grave y es sancionada con el destierro del patio.

La otra regla podría traducirse en lo que conocemos como derecho a la igualdad, que se refiere a que no existen preferencias frente a ningún privado de la libertad y, por tanto, todos son tratados como iguales por parte de la dirección.

Finalmente, se entiende como norma del patio las jornadas de educación ofertadas por los presos políticos, las cuales

[...] son de libre asistencia, aunque la dirección siempre, antes de comenzar, pasa a invitarnos a todos y se hacen en la rotonda. Se trata como temas de política y a mí me gusta mucho asistir a las sesiones que son como de leyes y sobre derecho en general, todo lo que conozco en 
este momento y que practico ahorita en la representación derechos humanos es lo que me han enseñado en las jornadas de educación. No es de obligatoria asistencia, casi siempre están solo los de las FARC, pero a veces va uno que otro. (Sebastián, comunicación personal, 27 de noviembre de 2017)

En este orden de ideas, el justo comunitario del patio 4 está configurado por los siguientes aspectos: 1) una suerte de código de convivencia consuetudinario que es reconocido e impuesto a todos los integrantes del patio; 2) se encuentra en permanente construcción y discusión entre todos los privados de la libertad; 3) es garantizado por una dirección colectiva de prisioneros políticos de las FARC-EP dotada de legitimidad; 4) dicha autoridad es la última instancia de decisión, pues interviene únicamente cuando las partes en conflicto no puedan solucionar las controversias por sus propios medios; 5) establece sanciones que no implican el uso de la violencia.

Estos cinco elementos son los que permiten que en el patio 4 el estado de convivencia sea mayoritariamente pacífico, pues se rigen por un justo comunitario propio de un pluralismo jurídico comunitario que gestiona conflictos de manera eficiente y democrática, respondiendo a las necesidades de la población privada de la libertad.

\section{CONCLUSIONES Y REFLEXIONES FINALES}

A través del estudio de caso de la comunidad LGBT fue posible la aproximación a un pabellón muy particular, el de los presos políticos, es decir, los guerrilleros de las FARC-EP. Este patio ha construido un ejercicio regulatorio de la convivencia completamente diferente al de los otros patios, precisamente porque el liderazgo lo tienen ellos, "que son revolucionarios" —como les dicen los de la comunidad LGBT-, edificando así, un justo comunitario que muestra ser más democrático, igualitario y menos violento y discriminatorio.

Esto muestra la heterogeneidad que puede componer una cárcel, y, en consecuencia, la multiplicidad de sistemas normativos que coexisten dentro de un espacio tan pequeño a escala social. Como señalaba Sebastián: "Yo sé que los patios que se pueden decir más tranquilos son el patio cuatro, en el que estoy; el patio seis, que es el de los extranjeros, de donde viene Paulina, ${ }^{17}$ que es ecuatoriana; y también el patio cinco, que es el de los violos, violadores, mejor dicho, son solo señores viejos, no suelen hacer nada, son muy tranquilos".

Respecto a los demás patios no es posible aseverar mayor cosa, pues extralimita los objetivos del presente estudio adentrarme en esas otras dinámicas; sin embargo, es posible señalar que en el patio 4 de La Picota se encontró una excepcionalidad a la norma social general de violencia y mafia que se vive por lo general en los patios de la gran mayoría de cárceles en Colombia.

Esta excepcionalidad del justo comunitario del pabellón 4, de la estructura 1, del complejo carcelario y penitenciario metropolitano de Bogotá "Comeb" - La Picota-, puede ser apreciada en varios aspectos: 1) reafirma la idoneidad de aproximarse teóricamente desde el pluralismo jurídico comunitario a un fenómeno social como el de las dinámicas internas de la cárcel; 2) permite entender por qué la comunidad LGBT de La Picota se encuentra, en su gran mayoría, en el patio de los presos políticos donde no son discriminados; 3) demuestra la posibilidad de construir dinámicas de sana convivencia intramuros en los centros penitenciarios; 4) aporta grandes insumos para programas de mediación de conflictos al interior de las cárceles, los cuales el INPEC ha tratado de implementar; ${ }^{18} 5$ ) disminuye el alto índice de violencia del sistema carcelario; 6) reduce el consumo, y en consecuencia el expendio, de sustancias sicoactivas; 7) reproduce valores democráticos; 8) expone la existencia de comunidades, bajo la óptica de Tönnies, dentro de las cárceles, que se preocupan por sus miembros, y que tratan de hacer un poco más justa su injusta realidad; y finalmente, 9) aporta, en algún nivel, aprendizajes claves a la hora de pensar en la resocialización de los privados de la libertad.

17 Una mujer trans, que es líder de la comunidad LGBT de La Picota y colaboró con el presente estudio.

18 Durante más de cuatro años "Cárceles para la paz" ha sido un proyecto de inversión del Departamento Nacional de Planeación cuyo objetivo es establecer un sistema de gestión de conflictos al interior de las cárceles colombianas (INPEC, 2017). Para esto ha contratado a la Escuela de Justicia Comunitaria de la Facultad de Derecho, Ciencias Políticas y Sociales de la Universidad Nacional de Colombia, pero los frutos de este esfuerzo han sido bastante limitados principalmente por dos aspectos: 1) los recursos económicos destinados han sido pocos, y 2) las actividades exigidas por el INPEC y desarrolladas en el marco de estos proyectos han estado completamente desarticuladas entre ellas. 
Espero que los resultados de este estudio puedan ser una posibilidad de visibilizar estos pequeños mundos que ignoramos -o que consideramos inexistentes - pero que muestran la posibilidad de hacer algo que transforme. Es quizá una muestra de que sí es posible pensar un sistema carcelario diferente, que las lógicas de la guerra no son el único camino a la hora de idear las políticas penitenciarias de Colombia.

Finalmente, este trabajo es evidencia de la posibilidad de investigar un fenómeno social de manera rigurosa, sin estar atados al método científico tradicional. Este es en gran medida también un compromiso político por abonar al terreno de la deconstrucción del positivismo dogmático, que ha sido cómplice y legitimador de la dominación, la explotación y la violencia.

Solo quedó un cuestionamiento sin resolver y es con respecto a la situación de la comunidad LGBT de las cárceles en la actual coyuntura de paz. Los guerrilleros están saliendo a la libertad y cuando no queden más dentro de las prisiones ien dónde van a ser recibidos los gais, bisexuales, y trans? Cuando ya iba saliendo de la Picota, me estaba despidiendo de Sebastián y le hice exactamente esa pregunta, y me respondió con preocupación: "Jum, no sé, y en mi patio ya solo quedan como cien" (Sebastián, comunicación personal, 27 de noviembre de 2017). 


\section{REFERENCIAS}

Ardila, E. (2006). ¿A dónde va la justicia en equidad en Colombia? Bogotá: Corporación Región.

Ardila, E. (s.f.). Justicia comunitaria y sociedad nacional: apuntes alrededor de la experiencia colombiana. Bogotá: Just Governance Group y Ashoka.

Clemmer, D. (s.f.). The Prison Commuity. Recuperado el 12 de marzo de 2018 de https://books.google.com.co/books?redir_ esc $=y \& h l=e s \& i d=x 7 M R C V 0-z c Y C \&$ focus $=$ searchwithinvolume $\& q=$ the

De la Cuesta Arzamendi, J. L. (1993). La resocialización objetivo de la intervención penitenciaria. Justiforum: Papers d'estudis i formació, n. 12. Catalunya, España.

Defensoría Delegada para la Política Criminal y Penitenciaria. (2009). Situación de las personas identificadas como del colectivo LGBT privadas de la libertad en cárceles de Colombia, Recuperado el 22 de febrero de 2018 de http:// www.defensoria.org.co/red/anexos/pdf/02/ informe_152.pdf

Espinosa, N. (2010). El justo comunitario, las leyes y la justicia en una región con fuerte presencia del conflicto armado. Etnografía del pluralismo jurídico en la Sierra de La Macarena. Diálogos de Derecho y Política, n. ${ }^{3}$, pp. 1-26. Bogotá, Colombia.

Foucault, M. (1969). La verdad y las formas jurídicas. International Review of Administrative Sciences (vol. 35). Inglaterra, Reino Unido.

Foucault, M. (1985). Nuevo orden interior y control social. Saber y verdad. España: De La Piqueta Edición.

Goffman, E. (2001). Internados: ensayos sobre la situación social de los enfermos mentales. Argentina: Amorrortu Editores.
Gómez-Peresmitré, G. y Reidl, L. (2016). Metodología de investigación en ciencias sociales. México: Editorial UNAM.

Instituto Rosarista de Acción Social, Seres. (2011). Desarrollo del sistema penitenciario y carcelario colombiano entre 1995 y 2010, en el marco de las políticas de Estado a partir de las sentencias de la Corte Constitucional. Bogotá: Editorial Universidad del Rosario.

Instituto Nacional Penitenciario y Carcelario, INPEC- (2017) Proyecto de Inversión Cárceles para la paz. Recuperado el 13 de mayo de 2018 de http://www.inpec.gov.co/institucion/ informacion-financiera/proyectos-de-inversion/-/document_library/CgeSTeLFBHmx/ view_file/76834

KienyKe Editorial. (2014). ¿Es efectiva la resocialización de los presos? KienyKe. Recuperado el 11 de octubre de 2017 de https://www.kienyke. com/krimen/es-efectiva-la-resocializacionde-los-presos

Macluf Escudero, J., Delfín Beltrán, L. A. y Gutiérrez González, L. (2008). El estudio de caso como estrategia de investigación en las ciencias sociales. Revista Ciencia Administrativa, n. ${ }^{\circ}$ 1. México.

Muñoz Conde, F. (1979). La resocialización del delincuente. Análisis y crítica de un mito. Revista de ciencias sociales, n. ${ }^{\circ} 31$. España.

Otzen, T. \& Manterola C. (2017). Técnicas de muestreo sobre una población a estudio. International Journal of Morphology. Chile.

Red Comunitaria Trans (2015). Cuerpos en prisión, mentes en acción. Cartilla para la defensa de los derechos de las mujeres trans y hombres gais privados de la libertad. Recuperado el 22 de agosto de 2017 de https://issuu.com/ cuerposenprisionmentesenaccion/docs/cuerpos_..e560e2f503a4fd 
Rivera, J (2011) Las Maras. El fenómeno criminal del siglo XXI. Recuperado el 16 de noviembre de 2017 de https://www.galileo.edu/ies/files/2011/04/ LAS-MARAS.-El-Fen\%C3\%B3meno-criminaldel-siglo-XXI.-Ensayo.pdf

Universidad Mayor de San Simón. (2009). Estado del arte: justicia comunitaria. Recuperado el 13 de agosto de 2017 de https://es.scribd. com/document/328836261/Estado-Del-ArteJusticia-Comunitaria

Van Dijk, T. A. (1999). El análisis crítico del discurso. Barcelona: Anthropos. 186, pp. 23-36.

Van Evera, S. (2002). Guía para estudiantes de ciencia política. Métodos y recursos. España: Editorial Gedisa.
Vasilachis, I. (2003). Pobres, pobreza, identidad y representaciones sociales. España: Editorial Gedisa.

Wacquant, L. (2010). Las cárceles de la miseria. Argentina: Editorial Manantial.

Wolkmer, A. C. (2006). Pluralismo jurídico: fundamentos de una nueva cultura del derecho. España: Editorial MAD.

Zehr, H. (2007). El pequeño libro justicia restaurativa. Recuperado el 4 de abril de 2018 de http://www.icbf.gov.co/portal/page/portal/ PortallCBF/bienestar/proteccion/responsabilidad-penal/justicia-restaurativa/Howard Zher - El pequeño Libro de la Justicia Restaurativa.pdf 
